\title{
Developments of Electrical Joints for Aluminum-Stabilized Superconducting Cables
}

\author{
P. Fabbricatore, S. Farinon, R. Musenich, C.Priano \\ Istituto Nazionale di Fisica Nucleare, Via Dodecaneso 33, 16100 Genova - Italy \\ B. Curé \\ CERN, European Laboratory for Particle Physics - Geneva - Switzerland \\ I. Horvath \\ ETHZ, Eidgenössische Technische Hochschule - Zürich - Switzerland
}

\begin{abstract}
Electrical joints for the aluminum-stabilized conductors of the LHC experiment magnets have been studied. Two techniques have been tested: electron beam welding and MIG welding. The joint resistance was measured as a function of the magnetic field on ring shaped samples using the MA.RI.S.A. test facility, wherein current is induced in the test conductor by a varying magnetic field. The resistance is obtained by measuring either the voltage drop or the decay time. Calculation and finite-element simulation have been performed in order to separate the effect of both the copper-aluminum contact resistivity and the aluminum resistivity from the effect due to the joint technique (joint configuration, resistivity of the filler material, increasing of aluminum resistivity in the welding zone). The copperaluminum contact resistivity and the current transfer length were obtained by measurements of the joint resistance of butt welded samples.
\end{abstract}

\section{INTRODUCTION}

The Large Hadron Collider (LHC) is the next important project of CERN, the European Laboratory for Particle Physics. The two major LHC detectors ATLAS and CMS are based on superconducting magnets, which will provide toroidal and solenoidal magnetic fields respectively. High purity aluminum-stabilized superconductors are used in the design and manufacture of these magnets. The conductors consist of a Rutherford type cable embedded in a highpurity aluminum matrix using an extrusion process. Different conductor cables and cross sections are considered for these magnets.

The design and manufacturing steps of these magnets require electrical joints, as the magnets will be manufactured from several lengths of co-extruded conductor. The magnets are operated at a nominal current of $20 \mathrm{kA}$ at liquid helium temperature, so the electrical resistance of the joints must be kept low enough not to alter the enthalpy margin and endanger the magnet stability. Furthermore, the joining techniques must not degrade the superconducting properties of the Rutherford cable.

In order to achieve joint electrical resistance lower than $10^{-9} \Omega$, the following joining techniques have been investigated: Electron Beam (EB) welding and Metal Inert Gas (MIG) welding.

EB welding provides a very high power density allowing a confined heat input in a narrow and deep penetrating weld, without the use of a filler material. This technology produces a full penetration weld with only a low temperature increase on the Rutherford cable.

Originally, the EB weld process was favored as it offers a full contact of each joined length. Finite-element modelisation showed that the electrical resistance due to the pure aluminum stabilizer is less than $10 \%$ of the total resistance, hence non full penetrating processes such MIG welding have been also studied.

The MIG welding process is more versatile compared to EB welding. It induces a lower heat input in the base material compared to conventional arc welding. The use of a low electrical resistance filler can lead to acceptable level of joint resistance with appropriate weld geometry.

\section{BASIC ASSUMPTION AND THEORY}

The resistance of a joint between aluminum-stabilized superconducting cables can be considered as the sum of three contributions: the contact resistance, the aluminum resistance and the weld resistance. The contact resistance comes from the contact quality between the niobiumtitanium superconducting filaments and the aluminum stabilizer and in particular from the intermetallic phases formed during manufacturing steps and due to diffusion processes of niobium, titanium, copper, aluminum and impurity atoms. The contact resistance value depends on the type, quantity and thickness of the phases and thus on the wire characteristics and on the conductor fabrication process. The aluminum resistance depends on the impurity contents and microstructural state. The weld resistance, directly related to the joining technique, is the resistance of the filler material.

To separate the three contributions, the measured resistance of butt welded joints has been analyzed by using a simple model (see Fig. 1.).

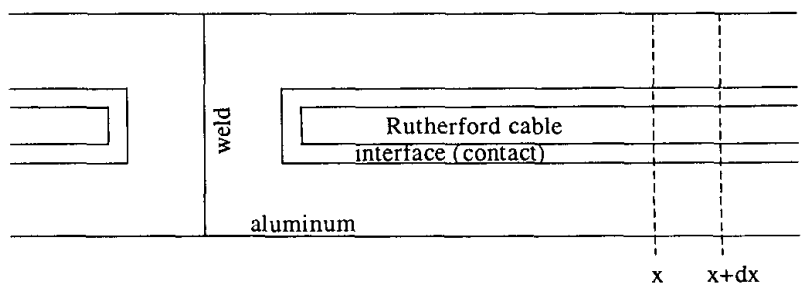

Fig. 1. Simple model of butt welded joint. 
The resistance $R$ due to the contact between $x$ and $x+\Delta x$ is:

$$
\mathrm{R}=\rho_{\mathrm{c}} \frac{\mathrm{t}}{\mathrm{p} \cdot \Delta \mathrm{x}}=\frac{\mathrm{r}}{\Delta \mathrm{x}} \mathrm{r}[\Omega \mathrm{m}]
$$

where $\rho_{c}, t$ and $p$ are the interface material resistivity, the interface thickness and the cable perimeter, respectively, and $r$ is the contact resistance. The voltage drop between the aluminum and the Rutherford cable is given by:

$$
\mathrm{V}_{\mathrm{Al}}(\mathrm{x})=\mathrm{r} \frac{\mathrm{dI}(\mathrm{x})}{\mathrm{dx}}
$$

while:

$$
\frac{\mathrm{dV}_{\mathrm{Al}}(\mathrm{x})}{\mathrm{dx}}=\mathrm{r}_{\mathrm{Al}} \mathrm{I}(\mathrm{x}) \quad \mathrm{r}_{\mathrm{Al}}[\Omega / \mathrm{m}]
$$

where $r_{A l}$ is the aluminum resistance per unit length. Substituting I(x) from (3) into (2), we obtain:

$$
\frac{d^{2} I(x)}{d x^{2}}=K^{2} I(x), \quad K^{2}=\frac{r_{A l}}{r}
$$

The solution of the equation is:

$$
\mathrm{I}(\mathrm{x})=\mathrm{I}_{0} \cdot \mathrm{e}^{-\mathrm{Kx}}
$$

provided the superconducting cable length is at least twice longer than the current transfer length, defined as:

$$
\lambda=\sqrt{\frac{\mathrm{r}}{\mathrm{r}_{\mathrm{A} l}}}=\frac{1}{\mathrm{~K}} \quad \lambda[\mathrm{m}]
$$

From the resistance values measured on the butt-welded joints $R_{j}$, the transfer length is calculated using:

$$
\lambda=\frac{\left(\mathrm{R}_{\mathrm{j}}-\mathrm{R}_{\mathrm{Al}}^{*}\right)}{2 \cdot \mathrm{r}_{\mathrm{Al}}}
$$

and the contact resistance $r$ can be easily found with:

$$
\mathrm{r}=\frac{\left(\mathrm{R}_{\mathrm{j}}-\mathrm{R}_{\mathrm{Al}}^{*}\right)^{2}}{4 \cdot \mathrm{r}_{\mathrm{Al}}}
$$

where $\mathrm{R}_{\mathrm{Al}}^{*}$ is the resistance of the aluminum between the two sample ends.

This model allows both the current transfer length and the contact resistivity to be calculated from the measured aluminum resistance. The contact resistivity is used to calculate the resistance of overlapped joints.

\section{Finite ELEMENT CALCULATION}

Calculations were performed with two separate finiteelement codes: CASTEM ${ }^{\circledR}$ (at CEA-Saclay) and ANSYS ${ }^{\circledR}$ (at INFN-Genova). The superconducting cable is modeled as a homogenous isotropic material of rectangular crosssection. The aluminum to superconducting cable contact is modeled as a thin layer material of electrical resistivity $\rho_{c}$ according to (1). The thickness of the layer is arbitrary fixed to $0.1 \mathrm{~mm}$. The pure aluminum stabilizer and the weld seam are modeled as homogenous isotropic materials with an electrical resistivity given by both the RRR and the external magnetic field, where:

$$
R R R=\rho(293 \mathrm{~K}, 0 \mathrm{~T}) / \rho(4.2 \mathrm{~K}, 0 \mathrm{~T})
$$

The models take into account the plane of symmetry along the joint and are meshed using cubic elements with 8 nodes.

\section{EXPERIMENTAL PROCEDURES AND RESULTS}

\section{A. Joint preparation}

The test sample rings were prepared from a conductor co-extruded with a cross section of $72 \times 9.8 \pm 0.05 \mathrm{~mm}^{2}$, using a 32 strand Rutherford cable. The typical properties of the conductor are in Table I. The cable is centered in the pure aluminum matrix. The conductor was machined to reduce the width from $72 \mathrm{~mm}$ to $32 \pm 0.1 \mathrm{~mm}$ before the joining operation. Several test rings were prepared: three butt welded joints, three EB welded joints, with an overlap of respectively $100 \mathrm{~mm}, 200 \mathrm{~mm}$ and $500 \mathrm{~mm}$, and two MIG welded joints, with an overlap of respectively $200 \mathrm{~mm}$ and $400 \mathrm{~mm}$. Fig. 2 gives a view of these test rings.

The samples were welded at CERN Central Workshop using the EB and MIG facilities: $\mathrm{EB}$ gun $70 \mathrm{kV} / 30 \mathrm{~kW}$, in a vertical position, with a $10^{-5}$ mbar vacuum chamber of $10 \mathrm{~m}^{3}$; pulsed MIG, with the arc in vertical position. All the rings were in horizontal position during welding.

The EB butt welded test rings are designed to measure the joint electrical resistance, including both the transfer length and the contact resistance between the superconducting cable and the aluminum stabilizer. The rings are made by butt welding a conductor where the superconducting cable is removed by machining carefully a groove about $2 \mathrm{~mm}$ deep at both ends, so that the current is forced to flow through the aluminum. A defined length of conductor is cut, machined, then bent on the proper radius; the two extremities are put into contact and fixed. Then the two extremities are EB welded in the vacuum chamber. The EB weld is $5 \mathrm{~mm}$ thick. A dedicated sample holder in aluminum alloy 5086 allows keeping the magnetic forces.

The EB overlapped joint test rings are plane spiral shaped. A specific forming tool gives the external shape of the spiral. Then the two overlapping extremities are fixed and EB welded in the vacuum chamber. The weld is a few mm thick. The temperature measured on the cable during preliminary EB weld tests reached $160^{\circ} \mathrm{C}$. A specific sample holder in aluminum alloy 6082 keeps the magnetic forces.

TABLE I

CONDUCTOR PROPERTIES

\begin{tabular}{ll} 
Wire & \\
\hline Strand diameter & $1.232 \mathrm{~mm}$ \\
Twist pitch & $50 \mathrm{~mm}$ \\
Cu/NbTi ratio & 1.25 \\
\hline Cable & $\cdot$ \\
\hline Number of strands & 32 \\
Thickness & $2.25 \mathrm{~mm}$ \\
Width & $21.0 \mathrm{~mm}$ \\
Transposition pitch & $110 \mathrm{~mm}$ \\
Compaction factor & 0.865
\end{tabular}




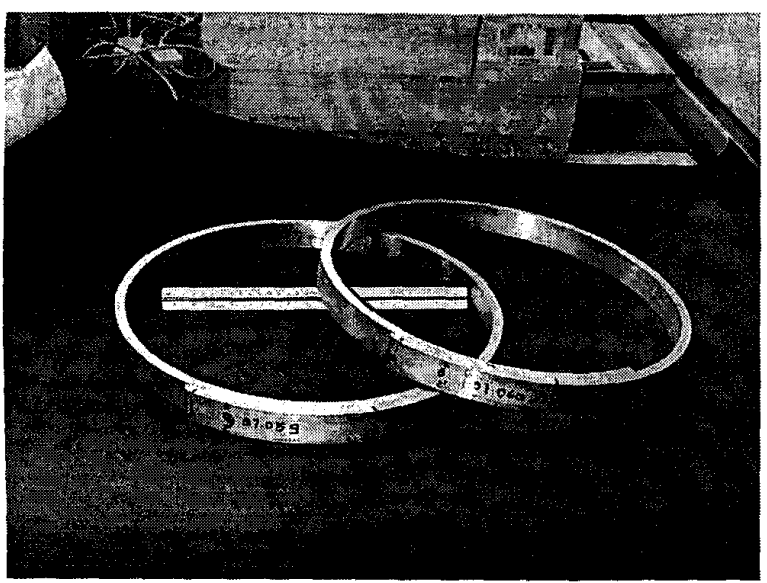

Fig. 2. View of the test rings.

The MIG overlapped test rings were manufactured using the same forming tool as the EB overlapped joint rings. The tests are performed with the same sample holder as the EB overlapped joints. The samples are welded on both side of the overlap. The maximum temperature measured in the pure aluminum stabilizer reached $201{ }^{\circ} \mathrm{C}$ at $0.75 \mathrm{~mm}$ distance from the cable. A chamfer $3.5 \mathrm{~mm}$ deep at an angle of $45^{\circ}$ is machined. The filler material is aluminum 1050 (99.5\%).

\section{B. Measurement method}

The joint sample resistance has been measured by the direct transformer method [1] using the MA.RI.S.A. test facility [2]. The test rings act as the secondary winding of a transformer, the primary is the background magnet. The current is induced in the samples by lowering the magnet current. Two methods are used to obtain the resistance values: the direct measurement of the voltage drop and the measurement of the current decay time. The latter is limited at low resistance values $\left(<5 \cdot 10^{-9}\right)$. Measurement accuracy is typically $\pm 10 \%$. By measuring the joint resistance of butt welded samples, the transfer length and the contact resistance can be found using respectively (7) and (8).

\section{Results}

The RRR of the conductor pure aluminum stabilizer was measured and was found equal to 1500 .

As the EB welding is performed without the use of a filler material and under vacuum, the impurity content in the weld is kept low, hence it was assumed in the calculations that the weld seam has an electrical resistivity equal to the one measured on the pure aluminum stabilizer of the conductor.

The weld of the MIG configuration was modeled with a RRR equal to 10 in the finite-element simulations.
The results of measurements and calculations are given on Fig. 3 to Fig. 6.

As shown on Fig. 3, the behavior of the contact resistance is fitted by a parabolic curve, whereas the transfer length is fitted by a linear curve.

\section{DISCUSSION}

The contact resistance and transfer length are strongly field dependent, as it appears on Fig. 3, and have an important influence on the total joint resistance.

Actually, on Fig. 4 the joint resistance does not show the field dependence that would be expected if the resistance was only due to the aluminum (both stabilizer and weld). Furthermore, results in Table II show that the aluminum stabilizer has low influence on the total resistance of the joint, which is mainly affected by the contact resistance.

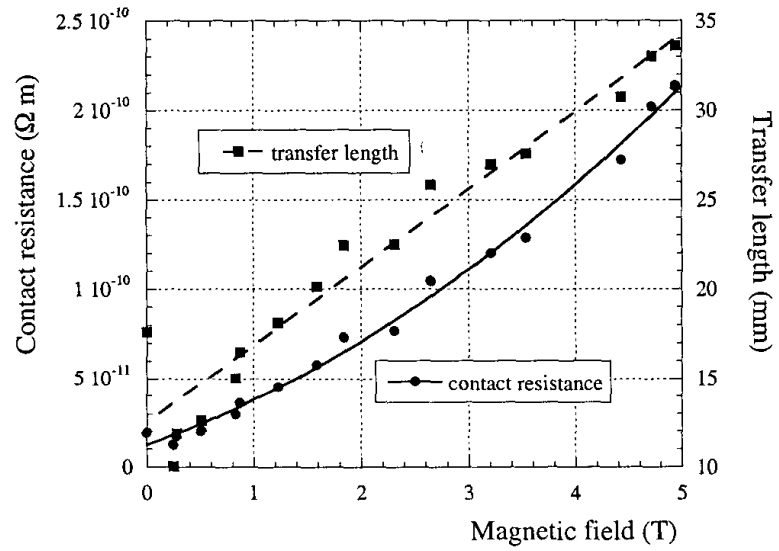

Fig. 3. Contact resistance and transfer length obtained from butt welded sample joint measurements.

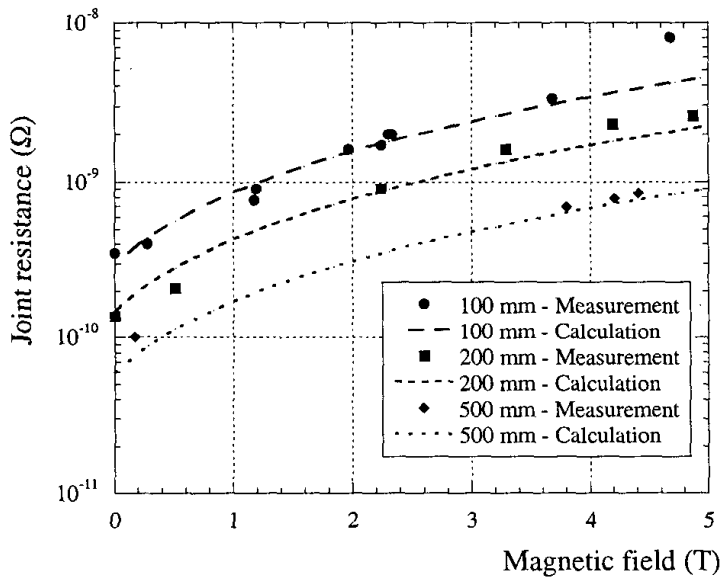

Fig. 4. Measurements and calculations on overlapped EB welded samples. 


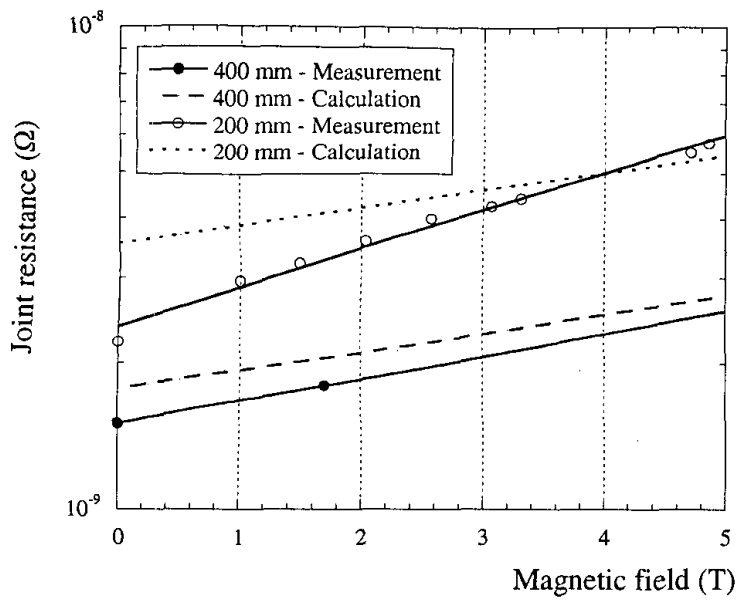

Fig. 5. Measurements and calculations on overlapped MIG welded samples.

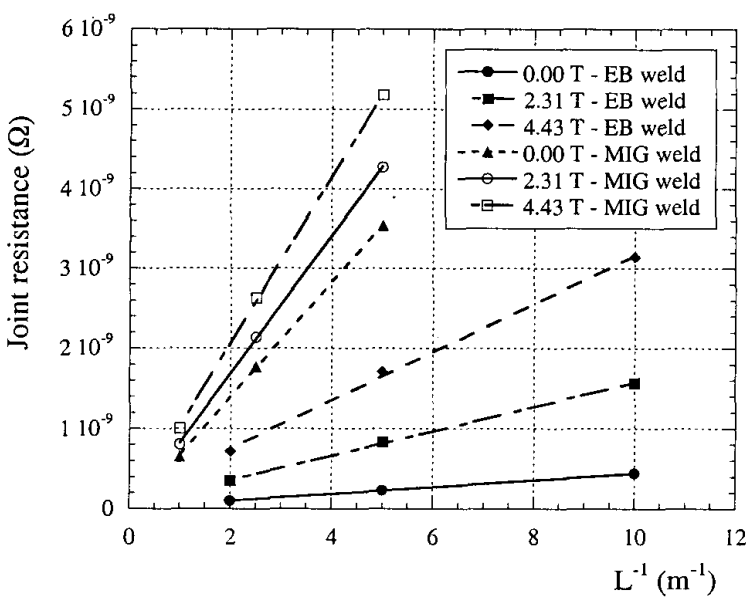

Fig. 6. Calculated joint resistance at different fields as function of joint length $\mathrm{L}$ for $\mathrm{EB}$ and MIG welded joints.

As consequence the $\mathrm{EB}$ behavior is parabolic as it is strictly dominated by the contact resistivity, which is best fitted by a parabolic curve. It is worth noting that the behavior of the $100 \mathrm{~mm}$ long EBW joint as function of field is not parabolic but exponential, not in agreement with the calculation as shown in Fig. 4. This behavior is probably due to the short length of the welding, about a factor two lower than the transposition pitch (not considered in the finite-element simulations).

The MIG measurements, on Fig. 5, are not as well fitted as the EB ones, the slope being different between measurements and calculations. The slope of the MIG joint resistance is not decided by the resistivity of the weld, which does not depend on the field, but by the term containing the contact resistivity, which depends on the field: $r / L$, with $r$ contact resistance and $L$ joint length. Since $r$ is a parameter of the conductor itself, measured with the tests of butt welded samples, a better fit of the MIG measurements could only be obtained by changing the $L$ value; in the case of the $200 \mathrm{~mm}$ overlapped MIG
TABLE II

ALUMINUM STABILIZER AND CONTACT RESISTANCE AS PERCENTAGE OF TOTAL JOINT RESISTANCE FOR THE EB WELDED JOINTS

\begin{tabular}{lll}
\hline $\begin{array}{l}\text { Magnetic induction } \\
\text { on the samples }(\mathrm{T})\end{array}$ & $\begin{array}{l}\text { Contact resistance } \\
(\boldsymbol{\%})\end{array}$ & $\begin{array}{l}\text { Aluminum resistance } \\
(\boldsymbol{\%})\end{array}$ \\
\hline 0 & 91 & 9 \\
2.31 & 94 & 6 \\
4.43 & 97 & 3 \\
\hline
\end{tabular}

joint the correct slope is achieved for $\mathrm{L} \sim 150 \mathrm{~mm}$, instead of $200 \mathrm{~mm}$. Non destructive testing of the weld is therefore required, such as dye penetration test, to determine the effective welded length.

The calculations show that the joint resistances are inversely proportional to the joint length as shown on Fig. 6, and acceptable joint resistance can be achieved with reasonable length of joint.

\section{CONCLUSION}

The electrical resistance of a joint is mainly due to the contact resistance between the superconducting cable and the pure aluminum stabilizer, and from the welded joint itself.

For EB welded joint, the resistance is driven by the contact resistance between the superconducting cable and the pure aluminum stabilizer, whereas for the MIG welded joints with a 1050 filler, the resistance is driven by both the weld resistance and the contact resistance.

For the MIG joining process, aluminum filler with resistivity lower than the 1050 alloy could be used. In this case, it could be expected that the joint resistance would be again driven by the contact resistance between the aluminum superconducting cable and the pure aluminum stabilizer.

Joint resistance values reach lower than $10^{-9} \Omega$ with both $\mathrm{EB}$ and $\mathrm{MIG}$ welding techniques, on conductor length in the order of $1 \mathrm{~m}$, which is easy to produce on site and to handle.

\section{ACKNOWLEDGMENT}

The authors wish to thank Alain Hervé and Domenico Campi from CERN and François Kircher from CEA-Saclay for their support of this work, and Jean Claude Lottin now retired from CEA-Saclay for his suggestions on the finite-element modeling of electrical joints.

\section{REFERENCES}

[1] B. Seeber, Handbook of applied superconductivity, IOP Bristol and Philadelphia 1998.

[2] P. Fabbricatore, A. Matrone, A. Parodi, R. Parodi, C. Salvo and R. Vaccarone, "MA.RI.S.A. A test facility for research in applied superconductivity", Proceedings of ICEC2, Southampton July 1998. 